\title{
EL CONCEPTO DE "OPINIÓN PÚBLICA" EN MÉXICO (1820-1828)
}

Gerson Moreno Reséndiz*

RESUMEN: Mediante el análisis del concepto de opinión pública, se pretende resaltar la importancia política que tuvo en el desarrollo de la vida social y cultural de la primera mitad del siglo XIX mexicano. Su relevancia política radicaba en que a través de la opinión pública se quería sustentar la soberanía nacional surgida de la voluntad general. Sin embargo, la historia de los conceptos develará, además, que en la práctica política la reflexión sobre cómo formar opinión pública y quiénes pueden formarla, segmenta espacios sociales, genera mecanismos de inclusión y exclusión, y, sobre todo, propicia estados de ánimo derivados de la experiencia y la expectativa social.

\section{sose \\ THE IDEA OF “PUBLIC OPINION” IN MEXICO (1820-1828)}

ABSTRACT: Through an analysis of the concept of "public opinion", we will highlight its political importance in the development of Mexico's social and cultural life in the first half of the nineteenth century. Its political significance lies in that national sovereignty, originating from the people's will, was supported through public opinion. However, by studying the history of these concepts we will show that in the political exercise the reflection on the origin of a public opinion and of those who shape it divides the social sphere, produces inclusionary and exclusionary mechanisms, and above all facilitates certain moods due to social expectations and experiences.

PALABRAS CLAVE: opinión pública, diacronía, sincronía, Iturbide.

KEY WORDS: public opinion, diachrony, synchrony, Iturbide.

RECEPCIÓN: 8 de abril de 2016.

APROBACIÓN: 6 de septiembre de 2016.

* Doctor en Historia por la Universidad Iberoamericana. 
CITAM Derechos Reservados.

La reproducción total o parcial de este artículo se podrá hacer si el ITAM otorga la autorización previamente por escrito. 


\section{EL CONCEPTO DE "OPINIÓN PÚBLICA" EN MÉXICO (1820-1828)}

\section{Introducción}

\section{El término opinión pública está tan inte-} riorizado por la sociedad contemporánea que ha perdido totalmente su sentido de conflicto; es decir, en la actualidad los sectores de la sociedad han llegado a un consenso sobre cómo se forma la opinión pública. Para gran parte de las teorías modernas, la opinión pública se forma poniendo en circulación en el espacio social una gama de opiniones individuales sobre los asuntos de interés público. Según estas teorías, las opiniones vertidas tienen su origen en las diferentes formas comunicativas humanas (periódicos, radio, televisión, internet). De esta manera, las opiniones, al circular por los medios masivos de comunicación llevan a las diferentes teorías a considerar a estos medios como los formadores de la opinión pública o, de cierta manera, como fuertes influencias. ${ }^{1}$

Esto no era así para la sociedad mexicana de principios del siglo XIX. Los espacios de la publicidad moderna - los espacios en donde las opiniones privadas se transforman en públicas - eran totalmente nuevos, y la instauración de la libertad de imprenta fue para las élites cultas

${ }^{1}$ Cfr. Raúl Rivadeneira Prada, La opinión pública: Análisis, estructura y métodos para su estudio, 1995, México, Trillas; K. Young et al., La opinión pública y la propaganda, 2001, México, Paidós, trad. de Eliseo Verón y Jorge Siroli; Manuel Mora y Araujo, El poder de la conversación. Elementos para una teoría de la opinión pública, 2005, Buenos Aires, La Crujía. 
una de las "cosas más dignas para la ilustración de las naciones". El establecimiento de la libertad de imprenta facilitó la circulación de los periódicos, en los que cualquier persona podía dar su opinión acerca de los asuntos de interés público. No obstante, muy temprano esas mismas clases mostraron su desagrado y desprecio por las opiniones vertidas en "producciones indigestas enemigas del buen gusto [que] brotan a cada momento; sus prematuros partos se venden al vulgo inepto como rasgos admirables de elocuencia". ${ }^{2}$ A la par de los periódicos, las producciones "indigestas" se difundían en papeles sueltos llamados "panfletos", en los cuales se publicaban fábulas, cuentos, diálogos y libelos infamantes con el fin de insultar y criticar las decisiones, los actos y la persona de los actores políticos encargados del gobierno. Estas publicaciones, debido a su carácter sedicioso, comenzaron a ser relacionadas por las élites en el gobierno con una opinión vulgar, disgregadora de toda unión y orden social y, de esta forma, fueron consideradas como una opinión falsa, no constitutiva de opinión pública. Como contraparte, la verdadera opinión u "opinión pública" era relacionada con las opiniones útiles, virtuosas, racionales y de buen gusto, de lo que hay que entender que se refería a las opiniones vertidas por las élites en el poder y en consonancia con las decisiones del gobierno en turno.

Al circular diferentes tipos de opiniones en el espacio público, unas ciertas y virtuosas, las otras falsas y vulgares, el problema fundamental de la sociedad mexicana de inicios de la vida independiente consistió en aprender a distinguir entre la "verdadera" opinión pública y la opinión "falsa" y "sin fundamento", y desde luego, discernir quiénes eran sus portadores. En estos puntos radica el carácter polémico del concepto de opinión pública, pues en el ámbito político y social los individuos, grupos, facciones o partidos luchan por presentarse como los portadores de la "verdad" y "constituyentes de opinión". Con ello, sus acciones quedaban justificadas, pues la lucha que emprendían era en pos de la opinión pública o la voluntad de la nación. La polémica de ninguna

${ }^{2}$ La vapulación más cruel a escritores miserables, 1820, México, Imprenta de D. Alejandro Valdés, 5 p., Fondo Reservado de la Biblioteca Nacional de México (en adelante FRBNM), Colección Lafragua, Laf.260, ficha 21. 
forma era insignificante, pues los actores políticos de la época consideraban a la opinión pública el sostén de la soberanía política vertida del orden republicano.

\section{Qué es y cómo se forma la opinión pública}

En 1820, en las páginas de El Hispano-Americano Constitucional, Lorenzo de Zavala inició una serie de artículos intitulados "Cómo se forma la opinión pública". La definición de opinión pública con que comienzan los artículos le sirvió como punto de partida para su formulación:

Así como la voluntad general de un pueblo, que se expresa por medio de las leyes, es la reunión de las voluntades particulares de los ciudadanos acerca de los objetos de interés general, así la opinión pública no es ni puede ser otra cosa sino la coincidencia de las opiniones particulares en una verdad de que todos están convencidos. Cimentada ya por la reunión, que es el origen de la fuerza, la opinión general, entonces en vano se opondrán los intereses y las miras particulares a la voluntad de todos, que está encerrada en la opinión. ${ }^{3}$

Formada por la reunión de las voluntades particulares en pública discusión sobre los problemas que atañían al común, de la voluntad de la mayoría o la opinión general irrumpía la opinión pública. En otras palabras, en un espacio de participación y discusión racional emergía la opinión pública. Esta visión optimista del concepto de opinión pública abría la posibilidad de fundamentar un ambiente de esperanza sobre futuros acuerdos con miras al bien público.

Esta posibilidad y este optimismo todavía se mantuvieron en las sesiones del Constituyente Mexicano, instalado el 24 de febrero de 1822. En la sesión del 17 de junio, el diputado Martín Inclán dijo que no hallaba otra solución para conocer el bien público, que el público

${ }^{3}$ Lorenzo de Zavala, "Cómo se forma la opinión pública", El Hispano-Americano Constitucional, 13 de junio de 1820, citado en Elías José Palti, La invención de una legitimidad. Razón y retórica en el pensamiento mexicano del siglo XIX, 2005, México, FCE, pp. 77-78. 
mismo. "Hable el pueblo: escúchese su opinión; y generalizada esta, se formará el que todos los políticos llaman espíritu público: este grande agente de todos los gobiernos liberales que en expresión de un sabio, reina en el mundo suave, pero más poderosamente que las armas de los tiranos". ${ }^{4}$ Hay que puntualizar, sin embargo, que la noción de opinión pública expuesta no implicaba la opinión de cualquier persona ni mucho menos la del "vulgo ignorante", que las élites de la época veían con miedo y desprecio. La parte del "pueblo" al que hacía referencia el señor Inclán conformaba la parte "ilustrada" de la sociedad mexicana, pues más adelante continuaba argumentando:

No confundo la voz popular con la opinión pública: esta en su genuina definición, es la expresión general del pueblo convencido de la verdad, que ha examinado por medio de la discusión; cuando aquella es el efecto del error, de la ignorancia de la violencia, de otras causas: por eso no se debe oír al vulgo ignorante, sino a la parte ilustrada del pueblo [...] No hay ni puede haber otro tribunal para decidir de la opinión pública, que el tribunal de la razón y del sentido general de los hombres. ${ }^{5}$ [Las cursivas son mías.]

Al mismo tiempo, reflexionaba que los hombres no podían juzgar ni explicar su parecer si no se escribía con mayor libertad. A su juicio, no había nada de malo en hablar sobre las bases del Plan de Iguala y los Tratados de Córdoba si estos no resolvían los problemas de la nación y al hacerlo solo se buscaba el bien público: "Mientras los escritos no se publiquen; mientras la nación no pueda juzgar de ellos y examinar sus ideas [sic], no podrá contribuir en nada a la formación de la opinión pública, cuya administración es peculiar de los ciudadanos, y no de magistratura alguna; así como la razón debe ser el único juez, y la discusión el procedimiento más necesario". ${ }^{6}$

${ }^{4}$ Sesión del 17 de junio de 1822, en Fernando Zertuche Muñoz y Felipe Remolina Roqueñí (coords.), Enciclopedia Parlamentaria de México, serie I: Historia y desarrollo del Poder Legislativo, vol. II: Vida parlamentaria y obra de Juan A. Mateos, tomo I: Historia parlamentaria de los congresos mexicanos 1812-1822, 1997, México, Miguel Ángel Porrúa, H. Congreso de la Unión.

${ }^{5}$ Loc. cit.

${ }^{6}$ Ibid. 
De la misma forma, el "espacio de discusión racional" era visto como una especie de tribunal neutral para la conformación de la opinión pública: "No hay ni puede haber otro tribunal para decidir de la opinión pública, que el tribunal de la razón y del sentido general de los hombres". Esta manera de conformar la opinión era vista como una suerte de tribunal neutral que, con las evidencias y después de contrastar los argumentos, señalaba idealmente la verdad del caso; es decir, la "verdad" se mostraba por sí misma a todo ciudadano después de una discusión racional. La opinión pública, de esta forma, se constituía dentro de lo evidentemente racional, de lo que todo hombre honrado reconocía como bueno y como malo. El error, por el contrario, expresaba una desviación de las sanas costumbres, producto o bien de una mala apreciación de las normas sociales, o bien de alguna perversión (como el egoísmo, la codicia, las pasiones que atañen a todo hombre). Pero el error solo podía afectar a los hombres individualmente considerados; nunca podía convertirse en principios socialmente compartidos. ${ }^{7}$ Por ejemplo, un escritor que firmaba con las siglas A.A.F.C. en 1821 consideraba que para escribir solo se requería la expresión de las ideas; si eran buenas o malas, útiles o inútiles, saber distinguirlas dependía del buen juicio como parte de la crítica:

Me hallo firmemente persuadido que para escribir solo se requiere expresar las ideas; ahora, si estas son buenas o malas, útiles o inútiles, como son las sentencias tantas, cuantas las cabezas; así tiene lugar la crítica, pero no hay escritor que por malo que sea que no traiga su pedazo de moral, esto es, si el asunto que el autor se propone es bueno y útil para seguirlo, y si malo e inútil para aborrecerlo y saber huir de él. ${ }^{8}$

De la misma posición todavía era Joaquín Fernández de Lizardi hacia 1823, pues pensaba que "la opinión pública, por lo común, siempre es acertada, porque como al hombre le es innato apetecer el bien y

${ }^{7}$ Palti, op cit., p. 71.

${ }^{8}$ A.A.F.C., El que se quemare que sople, 1821, México, Imprenta Americana de D. José María Betancourt, 4 p., s/n, FRBNM, Colección Lafragua, Laf.215, ficha 31. 
huir del mal, se sigue que, queriendo el bien para todos, los más lo saben distinguir y casi siempre es buena la opinión pública".

Contrapuesto a la constitución de la opinión pública surgida de una deliberación democrática racional, la conformación de la opinión pública también era pensada como la formación exclusiva de unos cuantos, especialmente de los "sabios", pues no porque la mayoría acentuara algo, significaba que estuviera en lo cierto o que pudiera dilucidar lo mejor para el cuerpo social. En diversos escritos de 1821 se llamaba al gobierno a incitar a los sabios a expresar sus ideas por medio de la prensa: "Todo gobierno debe animar a los sabios para que escriban e instruyan a la Nación; debe poner la más reflexiva atención a sus trabajos que salen de sus manos, examinándolos, adoptar las verdades que demuestran y corregir los errores en que puedan caer". ${ }^{10}$

El "sabio", el "filósofo", el "hombre de letras", era aquel cuya profesión se centraba en cultivar la razón para aumentar la de los otros. Por este motivo, el "hombre de letras" ocupaba un lugar central en la visión política de las Luces. Era la figura alrededor de la cual se organizaba la idea de política racional. El "filósofo" era percibido como el portador de la razón, de esta forma, se convertía en una especie de sacerdote secular. La opinión pública, por tanto, no se confundía entonces en lo absoluto con la voluntad general; era resultado solamente del movimiento de confrontación de las ideas entre los filósofos, de donde resultaba el descubrimiento de la evidencia. Lo que creaba a la opinión pública era una discusión filosófica, una confrontación de expertos, y no un debate democrático. ${ }^{11}$ La fuerza de esta concepción crecía ante la constante publicación de panfletos en contra de personalidades del gobierno en los que, según sus detractores, los autores no enseñaban nada bueno ni instruían a la patria, pues no tenían más mira que la personalidad, la venganza y la detracción de los ciudadanos; con un

${ }^{9}$ Joaquín Fernández de Lizardi, El hermano del perico que cantaba la victoria. Periódico político y moral (1823), en Obras, vol. 64. Citado en Palti, op. cit., p. 70.

${ }^{10}$ El Amante de su Patria, Triunfo de los escritores por la libertad de imprenta, 1821, México, Imprenta de Alejandro Valdés, 11 p., s/n., FRBNM, Colección Lafragua, Laf.442., ficha 60.

${ }^{11}$ Pierre Rosanvallon, La consagración del ciudadano. Historia del sufragio universal en Francia, 1999, México, Instituto de Investigaciones Dr. José María Luis Mora, trad. de Ana García Bergua, p. 146. 
lenguaje particularmente obsceno, no producían ninguna honra y mucho menos algún bien. Para algunos, en México todavía no se había constituido la opinión pública, puesto que la libertad de imprenta - según su consideración - no se había establecido para el hombre de saber y de literatura, sino solo para los hombres ignorantes y de mal gusto.

Lo contrario sucede cuando solo hablan los escritores sabios amigos de la libertad, y de la patria, que lejos de contemporizar con las miras ambiciosas de un gobierno arbitrario, y de fomentar las inclinaciones erróneas de las facciones populares, solo se revisten de aquella moderación que es la primera cualidad de un escritor público que trata de buscar el equilibrio de la justicia y la verdad, para contener el uno e ilustrar a los otros, sin recurrir a los medios mezquinos de la intriga, la animosidad y los libelos. $^{12}$

Estas maneras de conformar la opinión pública tenían dos cosas en común. Primero, que provenían de una discusión racional, y por ende, segundo, dejaban fuera a una parte del "pueblo", el pueblo "iletrado e ignorante", incapaz de discernir lo bueno de lo malo, lo justo de lo injusto. De esta manera, en la formación de la opinión pública, era necesario mantener alejada de la discusión a esa parte del "pueblo", denominada en los escritos como "chusma", "pueblo ignorante", "léperos", "vulgo" y otros adjetivos. Esto se debía indudablemente a la experiencia indirecta de los sucesos de la Revolución Francesa y la experiencia directa, por ejemplo, del movimiento popular de Miguel Hidalgo:

Si esto no se verifica con la prontitud y celo que exige imperiosamente el bien de una independencia que tanto ha costado a nuestros conciudadanos, después de once años de fatigas de sangre, y de privaciones inauditas, nos veremos lastimosamente en el mismo caso que la Francia, de quien dice un escritor sabio y moderado de nuestro siglo, que después que habían sufrido calamidades tan crueles como las nuestras, y cuando la opinión pública logró por fin cimentarse sobre las bases de una monarquía moderada, que se consideró como el mejor de los gobiernos para un estado de tanta extensión, estas ideas saludables desaparecieron muy en

${ }^{12}$ El Amante de su patria, Triunfo de los escritores por la libertad de imprenta., op. cit. 
breve por la osadía de los escritores atolondrados que abismaron su patria en el caos de las facciones. El partido de la Corte, dice ese gran político, que creía haber conseguido todo lo que deseaba, y por otra los partidos de los ambiciosos que esperaban sacar ventaja para sí de las turbulencias públicas, lograron por diferentes medios extraviar la opinión, ya enterrando a los escritores que proponían principios y verdades, ya animando a los partidos, ya promoviendo sediciones populares, y dándoles el nombre de voz de la nación. En este conflicto de ambiciosos, en esta fecha tumultuaria de pasiones, el hombre virtuoso enmudeció ante la fuerza, y juzgó imposible ilustrar la patria en medio de los gritos y de los puñales. Desde entonces no hubo opinión pública. Los jornaleros de los arrabales, y el cuerpo de rameras de París, fueron órgano de la voz popular. Sus gritos eran proporcionados a la cantidad de dinero que habian recibido, y el grado de ferocidad que los jefes de las facciones habian conseguido inspirarles. La masa general cansada de tantos males, y desesperada de encontrar la felicidad, suscribía a todas las alteraciones de París, semejante a un enfermo desahuciado, a quien le es indiferente la posición que ha de tener en su lecho de muerte. ${ }^{13}$ [Las cursivas son mías.]

De esta manera, para poder cumplir la expectativa de formar una opinión pública en un espacio de discusión racional — pues esto traería consigo el bien común, y la posibilidad de ser la gran nación que en ese momento, entre 1821 y 1822, las publicaciones parecían mostrar-,${ }^{14}$

${ }^{13}$ Loc. cit.

${ }^{14}$ En este periodo, se vislumbró el Imperio de Iturbide como una gran potencia americana, aliada de Gran Bretaña y con posibilidades de expansión fronteriza. Antes de que se consumara la Independencia en 1821, muchos miembros de las élites novohispanas concibieron la nueva nación como un imperio: el Imperio de la América Septentrional. México, pensaban, fue un imperio antes de la llegada de los españoles y había formado parte durante tres siglos de la Monarquía española. Mientras la Junta Provisional Gubernativa del Imperio y el Congreso esperaba que Fernando VII o algún infante de la casa Borbón aceptara el trono de México, varios proyectos imperiales, además del iturbidista, se basaron en un tipo de mesianismo político, como el de Carlos María de Bustamante y fray Servando Teresa de Mier, que pensaban en una restauración del Imperio azteca, o el de Guadalupe Victoria, que estaba a favor de que ocupara el trono del imperio un oficial criollo, siempre que estuviera casado con una india noble, o, en fin, el atribuido a Alfonso Mancilla de Teruel, conde de Moctezuma, quien conspiró con Lorenzo de Zavala para entronarse con el nombre de Moctezuma III. Este imperio debería ser una gran potencia en la América Septentrional, "el país de las delicias", "el suelo de la abundancia", "la patria de los cristianos", "el apoyo de los buenos", "el país de los racionales", "la admiración del mundo". Ya coronado, Iturbide vislumbraba la expansión del imperio de la frontera oriental 
se debía expulsar a los "escritores ignorantes" o a los portavoces de esa parte del "pueblo ignorante". Entonces, como se puede observar, en su nivel semántico-sincrónico todas estas ideas de opinión pública remitían a una visión racional ilustrada e ideal de la función que debía tener o lo que debía ser la opinión pública. Pero en su nivel semánticodiacrónico vertido por la experiencia, el concepto generaba preguntas surgidas de la práctica política. ${ }^{15}$ ¿Cómo formarla?, ¿cómo discernirla? Estas preguntas venían de tales experiencias debido al desacuerdo generado por la diversidad de pareceres.

\section{Prensa, opinión e Iturbide}

La experiencia del Imperio de Iturbide muestra esa posibilidad, pero también reconfiguró la reflexión de cómo formar la opinión pública a quiénes debían ser los dirigentes de la opinión pública. Pero antes de pasar a explicar a que nos referimos, analicemos los sucesos que llevaron

hasta la isla de Cuba, a través de Yucatán, como un paso inicial en la búsqueda de la hegemonía de México sobre el Caribe. Cfr. Rafael Rojas, "Indicios de un imaginario imperial", en La escritura de la Independencia. El surgimiento de la opinión pública en México, 2003, México, Taurus/CIDE, pp. 65-85.

${ }^{15} \mathrm{La}$ historia social y la de los conceptos se caracterizan por presuponer teóricamente, aunque de modo distinto, la relación entre sincronía y diacronía. Desde la perspectiva sociohistórica se investiga la relación entre los acontecimientos sincrónicos y las estructuras diacrónicas. Y es una relación análoga la que se da entre un discurso hablado, sincrónico, y el lenguaje ya existente, diacrónico, que ejerce una influencia constante sobre el primero, la que se tematiza desde un enfoque histórico-conceptual. Puede que todo lo que suceda sea único y nuevo, pero no hasta el punto de no haber requerido determinadas condiciones sociales previas a largo plazo que hiciesen posible ese acontecimiento único. Puede que se acuñe un concepto nuevo que en palabras plasme experiencia y expectativas antes inexistentes; pero no puede ser tan nuevo como para no estar virtualmente presente en el lenguaje dado y no recibir su sentido del contexto lingüístico del que es heredero. Por tanto, ambos enfoques de investigación incluyen en la interacción entre discurso y acción, en la que los acontecimientos tienen lugar, la dimensión diacrónica — definida de forma distinta—, sin la cual la historia no es posible ni puede comprenderse. Reinhart Koselleck, Historias de conceptos. Estudios sobre semántica y pragmática del lenguaje político y social, 2012, Madrid, Trotta, trad. de Luis Fernández Torrez, p. 19. Cfr. también Sandro Chignola y Giuseppe Duso, Historia de los conceptos y filosofía política, 2009, Madrid, Biblioteca Nueva, trad. de María José Bertomeu; Gerson Moreno Reséndiz, "Historia de las palabras (history of speech) o historia de los conceptos (Begriffsgeschichte). Qué no es la historia de los conceptos en Reinhart Koselleck", en Historia y Grafía 45 (2016), México, Universidad Iberoamericana. 
a la coronación del emperador, y para hacerlo me centraré especialmente en la reconstrucción de Torcuato S. di Tella. ${ }^{16}$

Las primeras elecciones celebradas en el México independiente, entre diciembre de 1821 y enero de 1822, confirmaron el ambiente que se vivía, pues dieron por resultado un congreso muy heterogéneo, en el que no predominaba ningún grupo. Podían distinguirse iturbidistas, iturbidistas clericales, republicanos moderados y radicales con un pasado insurgente, además de expresiones que se inclinaban hacia los intereses provinciales o regionales. El gobierno provisional no pudo imponerse porque no había una voluntad gubernamental homogénea. Por lo tanto, la difusión de impresos, como otro tipo de acciones, sería un arma fundamental para generar una percepción de popularidad alrededor de la imagen de Iturbide. ${ }^{17}$ Por ejemplo, ya anteriormente, el 7 y 8 de octubre de 1821, hubo en Puebla manifestaciones organizadas por los clérigos partidarios de coronar a Iturbide. Un anónimo panfletista que registró el acontecimiento observó que no eran los ricos ni los poderosos los que habían proclamado a Iturbide, sino los humildes. Habían llevado retratos de Iturbide y exigieron que repicaran las campanas de la catedral, lo que fue concedido por el obispo Antonio Joaquín Pérez Martínez y también por el jefe político Carlos García y Bocanegra, por lo que no podía decirse que aquel hubiera sido un motín sedicioso. ${ }^{18}$ Otro autor recordó que, mil veces, la multitud había aclamado como emperador a Iturbide y que el hecho de que esa no fuese la opinión de la gente docta no le quitaba validez. ${ }^{19}$

El apoyo populista clerical se expresó en escritos como Yo no entiendo de estas cosas, en el que las anteriores autoridades virreinales eran acusadas de haber estado a punto de destruir la religión por aplicar las

16 "El cesarismo popular", en Torcuato S. di Tella, Política nacional y popular en México, 1820-1847, 1994, México, FCE, pp. 121-149.

${ }^{17}$ J. A. M., Contestación de un americano al manifiesto del Sr. D. A. de Iturbide (11 de octubre de 1811); El derecho del pueblo mexicano para elegir emperador (1821); Derechos convincentes para elegir emperador americano (1821); El grande asunto de hoy (1821), citados en ibid., p. 121.

${ }^{18}$ Manuel María Ramírez de Arellano, Legal solicitud importantísima o salva triple de artillería imperial (1821), citado en ibid.

${ }^{19}$ E. D. L., Realizado en Puebla el importante voto de un ciudadano (1821), citado en ibid. 
medidas liberales de las Cortes españolas, con ayuda de la comunidad mercantil del Parián, enemigos de la Independencia. En la misma línea, un ironista publicó un escrito en el que alababa a Iturbide por no establecer la tolerancia religiosa o una república, además de ridiculizar algunos de los argumentos oídos en los cafés en contra del "Libertador Iturbide". También en 1821 se publicaron dos números de un Tribuno de la plebe o escritos de los pelados, redactados en un estilo popular. Decían que la plebe era la mejor parte de la sociedad, formada por "labradores, artesanos, arrieros, mineros y todos los que trabajan para mantenerse", quienes soportaban los principios impuestos y, en las mayores ciudades, habían apoyado a los ejércitos de la libertad. ${ }^{20}$

Entre sus más cercanos colaboradores en la movilización de las prensas estaba Joaquín Fernández de Lizardi, quien desde septiembre de 1821 pedía la coronación de Iturbide, a pesar del llamado a respetar los Tratados de Córdoba. ${ }^{21}$ Lizardi sería parte de ese sector de escritores, designados por Rafael Rojas como el "arquetipo del panfletista político", situado entre la masa iletrada y la alta cultura. Una de sus principales características era su trabajo a sueldo para la causa de cualquier caudillo. ${ }^{22}$ Otro de los aduladores de Iturbide fue Pablo de Villavicencio, conocido como el Payo del Rosario, que llegó a la capital en 1822 y se hizo buen amigo de Lizardi.

Por su parte, Iturbide, desde el comienzo de su campaña contra el gobierno español, es decir, desde 1820, había emprendido ciertas medidas destinadas a hacerse popular entre sus soldados y sectores más numerosos de la población. Había prometido distribuir tierras a quienes se alistaran por más de seis meses. Iturbide también trató de ganarse a los negros, especialmente a los soldados realistas de Cuernavaca y de Cuautla, entre otros, los célebres "negros de Gabriel de Yermo", que habían sido liberados por su amo solo para que lucharan en contra de la causa insurgente.

${ }^{20}$ Citados en ibid., p. 122.

${ }^{21}$ Fernández de Lizardi, Un puñado de verdades a nuestros enemigos (12 de septiembre de 1821); El Pensador Mexicano al Exmo. Sr. Gral. del Ejército Imperial D. Agustín de Iturbide (29 de septiembre de 1821), citados en ibid.

22 "Una maldición silenciada” en Rafael Rojas, op cit., pp. 169-195. 
Durante abril y mayo de 1822 se produjo la confrontación más abierta entre Iturbide y el Congreso instaurado el 24 de febrero, debido al rechazo de los Tratados de Córdoba por parte de Fernando VII y las Cortes a mediados de marzo. Días después (3 y 5 de abril) sectores de las desmovilizadas tropas españolas que aguardaban su repatriación intentaron una acción a favor de Fernando VII, pero fueron reprimidas. Esto aumentó los temores acerca de la seguridad de la independencia, y caldeó todavía más los debates en el Congreso, con escenas violentas entre Iturbide y la mayoría de la oposición, con gritos de "traidor" entre ambos bandos. Los ataques se debieron a que José Dávila, comandante del castillo de San Juan de Ulúa, que permanecía aún en poder de España, intentó convencer a Iturbide de que "no eran los diputados del Congreso mexicano los pilotos que necesitaba una nave que surca por mares desconocidos y por escollos no situados" y que su existencia política estaba en contradicción con la de las Cortes mexicanas. Con el argumento de que la vida del imperio y del propio Iturbide peligraba, Dávila le propuso, a nombre de Fernando VII, la reconquista de México con el auxilio de tropas expedicionarias españolas que iban a restablecer una "decorosa dependencia que todavía importa tenga la Nueva de la antigua España". ${ }^{23}$

Al recibir esta propuesta de autogolpe de Estado, Iturbide convocó a una sesión extraordinaria del Congreso, celebrada el 3 de abril de 1822, informó a los diputados de la inminente intervención española y solicitó al Congreso que decretase un considerable incremento del ejército imperial a su mando. Sus demandas fueron rechazadas por un grupo de diputados, a los cuales Iturbide acusó de traición, por oponerse a una ley que determinaba la suerte de la patria, mientras que ellos también lo acusaron de traición, por haber sostenido correspondencia con el comandante de San Juan de Ulúa. A partir de este momento, Iturbide reactivó su propaganda en contra del Congreso. Son de suma importancia los argumentos expresados en sus proclamas, en los que se percibe cómo la alerta defensiva en que vivía el país por la amenaza de reconquista

${ }^{23}$ Rafael Rojas, op cit., pp. 75-76. 
se transformó retóricamente en un llamado a la ofensiva militar del Imperio, en una virtual invocación de la guerra:

Ya he repetido varias veces, que la Patria peligra, que por todas partes está amenazada, que tiene enemigos dentro y fuera de sus términos, que son sus asesinos los que la adulan, queriendo persuadirla de que nada hay que temer, y que su libertad e independencia está asegurada. He dicho repetidas veces que a estos males no se les conoce otro antídoto que mantener un Ejército de treinta y cinco mil hombres, distribuido, como he dicho también, y he dicho que sin Ejército y sin Hacienda, todo lo hecho hasta ahora es perdido, y servirá sólo para ponernos en peor condición [...] Por Walis $[\mathrm{sic}]^{24}$ nos amenazan los ingleses, por Tejas se interesan nuestros vecinos, por varios puntos de la frontera Oriente las naciones bárbaras, por Guatemala la anarquía, por las Californias los rusos, por Veracruz los españoles, por las provincias la guerra civil, y por todas partes todas las naciones de Europa. ${ }^{25}$

En sus proclamas de esos meses aparece siempre su persona como la única garantía del equilibrio del país, como el único caudillo capaz de hacer de México un imperio. Así, el 15 de mayo de 1822, tres días antes de la manifestación del regimiento de Celaya que propició su coronación, envió un ultimátum al Congreso:

Si no se decreta el ejército pedido, se destina a los puntos explicados, y se sistema la hacienda muy pronto, para que el mismo ejército esté alimentado, vestido, pagado, armado y provisto de cuanto necesita, en cuyo caso respondo de la disciplina de las tropas y de la seguridad del Estado, puede procederse por quien crea tener autoridad de hacerlo a nombrar general que mande y presidente de la Regencia, pues yo doy por admitida mi renuncia en el mero hecho de no ver el remedio, o de que no se me conteste: esta renuncia la hago y verificaré mi separación de todo mando, penetrado de que es un deber no dilatarlo: es imposible que haya quien no esté íntimamente convencido de las razones en que me fundo para

${ }^{24}$ Belice.

${ }^{25}$ Papel de S. M. Imperial dirigido al Supremo Consejo de Regencia (15 de mayo de 1822), citado en ibid., p. 77. 
pedir un ejército de treinta y cinco mil hombres, y si no se decreta, es solo porque se recela de que yo lo mande". ${ }^{26}$

El 17 de mayo, el Congreso se opuso a su petición argumentando que su política de reforzamiento militar sería un camino hacia el despotismo. El 18 se desató el golpe con ayuda de suboficiales como Pío Marcha, quien reclutó hombres entre los sectores más pobres de la ciudad en el sur y sudoeste: San Pablo, La Palma, Salto del Agua y la zona cerca de la garita de San Antonio Abad (Santa Cruz Acatlán, Necatitlán, El Matadero). A la mañana siguiente, el Congreso, apresuradamente convocado a deliberar, validó la proclama de Iturbide como emperador, aun si, estrictamente hablando, no tuvo cuórum. En esa sesión, celebrada entre grupos de frailes y hombres mal vestidos que ocuparon todos los lugares disponibles, Valentín Gómez Farías, diputado por Zacatecas, desempeñó el papel principal, pidiendo que se adoptara la decisión. La medida también fue aprobada por miembros distinguidos, como Lorenzo de Zavala, de Yucatán; José María Bocanegra, de Zacatecas; y José Ignacio Esteva, de Veracruz; todos ellos futuros miembros de la logia yorkina. Además, Iturbide contó con el apoyo de Juan José Espinosa de los Monteros y Andrés Quintana Roo. ${ }^{27}$

La movilización del sector popular fue argumento de la oposición para proclamar ilegítimo al emperador. ${ }^{28} \mathrm{El}$ malestar por la coronación de Iturbide no pasó desapercibido a la mayoría de la élite mexicana no adepta de Iturbide, ya que para ellos: "la toga purpurada no bastaba para hacer del exoficial un auténtico monarca". ${ }^{29}$ Pero lo que menos podían soportar era que este criollo hubiera sido encumbrado por una turba prevaricadora dirigida por un sector de la élite adepta a Iturbide. En efecto, para esta facción de la élite política mexicana, la opinión pública

${ }^{26}$ Ibid, p. 79.

${ }^{27}$ Di Tella, op. cit., p. 128.

${ }^{28}$ Aunque la oposición se valió de los mismos medios para derribar al emperador. En las memorias de Iturbide se menciona varias veces el apoyo de que sus enemigos gozaban entre negros y castas. Cuando Santa Anna se rebeló contra el imperio, "intimidó a los pueblos cercanos de Alvarado y Antigua, y a los de color de las rancherías inmediatas”, y "puso 200 pardos a las órdenes de Victoria en el punto estratégico de Puente Nacional". Ibid., p. 133.

${ }^{29}$ Palti, op cit., p. 64. 
había sido opacada por "la gritería y los puñales" de la "chusma", había cedido su lugar a una excitada opinión llevada por las clases bajas de la sociedad mexicana, y para colmo le dieron el nombre de "opinión nacional". La oposición a Iturbide argumentó que "la chusma" fue justamente la que se hizo presente en la elevación del emperador, no la razón. Esta parte de la nueva élite mexicana asoció a las clases bajas con el sector adicto a Iturbide, por ello su gobierno no podía ni debía tener legitimidad, pues no provenía de la opinión pública.

Los enemigos de Iturbide señalaron después de su deposición los aspectos populares de su apoyo. El panfletista liberal Rafael Dávila dividió

al pueblo común, al que aún le gusta ver a Iturbide en el trono, en dos clases: una que no se deja convencer por argumentos, que después de haber escuchado a muchos y muy convincentes sólo responde: [...] si era malo, por qué lo proclamaron emperador. Si no mató muchas vidas fue porque no quiso hacerlo y porque era un santo, entonces por qué los que hoy hablan contra él no abrieron la boca cuando estaba en el trono; con esta clase de hombres yo no hablo porque actúan como irracionales, solo por instinto; hablo con quienes dan lugar a la razón y pueden ser convencidos por la verdad. ${ }^{30}$

El mismo autor continuó analizando así la contraposición de intereses; "sólo la mayor parte de la clase media y un pequeño número de los otros estamentos aspira a la libertad; [Iturbide] se asoció con los más ambiciosos de la clase superior y media y con los más viles de las inferiores". ${ }^{31}$ De la misma forma, el autor de Muerte y entierro de Agustín Primero (1823) incluyó entre los deudos dolientes a un gran número de clérigos, viejas, monjes, fanáticos, multitudes con una vela en la mano izquierda y una navaja en la derecha, y "muchos leperillos, con veleta, al son de un tambor, pero en vez de armas, llevando cañaverales con rotulones", refiriéndose al hábito de aquellos días de llevar estandartes en las manifestaciones públicas. Entre otros, en esa imaginaria

${ }^{30}$ Rafael Dávila, Sea Iturbide al descubierto (1823), citado en Di Tella, op cit., p. 133.

${ }^{31}$ Loc. cit. 
procesión iban "un religioso mercedario, rodeado de algunos leperuscos". Sin duda, dice Di Tella, iba el padre Aguilar del convento de la Merced, calificado por Carlos María de Bustamante como "jefe de los demagogos" y que fue coronel del batallón de milicias reclutado por Iturbide entre los barrios bajos hacia el final de su régimen. El escritor descubrió también entre la procesión a los hermanos Mariano y Manuel Barreda, coroneles por aquel tiempo, que habían lucrado haciendo uniformes para el Ejército Trigarante y que después obtuvieron la concesión de recoger la basura de la ciudad. Se encontraban entre los principales jefes de la improvisada milicia otros personajes, como Luciano Castrejón, más conocido como el Marqués del Bodegón, Pío Marcha y sus sargentos, y otros varios improvisados coroneles. ${ }^{32}$

Al final de su gobierno, ante la revuelta encabezada por Antonio López de Santa Anna, a la que se sumaron Guadalupe Victoria, Vicente Guerrero y Nicolás Bravo, y cuando todo estaba perdido para el emperador, Joaquín Fernández de Lizardi le pidió a Iturbide que renunciara a la corona para su mayor gloria, y al mismo tiempo dilucidó cuál era la verdadera opinión pública que debía escuchar para sostenerse en el trono.

Es verdad que no le faltarán aduladores como siempre; pero estos serían algunos nobles, o frailes y vulgares de la última plebe, cuyos vivas y sufragios son alucinantes, pero de ningún valor. Mr. de Pradt dice que en 1814 en el Congreso de Viena el Lord Wellington sostuvo a su presencia que Fernando VII con sus frailes y populacho tenía lo más fuerte de la nación. Los hechos posteriores manifestaron su equivocación, y tales sujetos son un apoyo ridículo. En el estado medio consiste la fuerza física y moral; si con esta no cuenta S. M. el abdicar a la corona será su mayor gloria, porque acabará por manifestar que nada aprecia más que el bien de la patria. ${ }^{33}$

${ }^{32}$ Ibid., p. 134.

${ }^{33}$ El Pensador Mexicano, Por la salud de la patria se desprecia una corona, 1823, México, imprenta del autor, 8 p., FRBNM, Colección Lafragua, Laf.258, ficha 3. 


\section{Quiénes forman la opinión pública}

A partir de los acontecimientos que llevaron al trono a Iturbide, el problema de la opinión pública tenía que sufrir una restructuración, que se produjo ya en la etapa republicana, en agosto de 1825. En el periódico $\mathrm{El} \mathrm{Sol} \mathrm{apareció} \mathrm{una} \mathrm{serie} \mathrm{de} \mathrm{artículos} \mathrm{con} \mathrm{el} \mathrm{título} \mathrm{"Ensayo} \mathrm{sobre}$ la opinión pública" ${ }^{34}$ que, curiosamente, se repitieron íntegramente el 2 de enero de 1828 en las páginas del Observador de la República Mexicana, como "Discurso sobre el modo de formarse la opinión pública". ${ }^{35}$ Los escritos giraban en torno a la pregunta sobre cómo se formaba la opinión pública. La importancia de dar una respuesta radicaba en el peso trascendental de la opinión pública como sostén de la soberanía: "Si no queremos pues, fluctuar continuamente entre la anarquía y el despotismo, es necesario formar un lazo que una estos dos extremos, cuya oposición es solo aparente, y este lazo no puede ser otro sino la opinión pública". ${ }^{36}$ Así, a nivel sincrónico, el concepto de opinión pública no sufrió ningún cambio en su acepción semántica, pues se seguía concibiendo como "la voz general de todo un pueblo convencido de una verdad, que ha examinado por medio de la discusión". ${ }^{37}$ Cimentada por la reunión, "que es el origen de la fuerza", entonces, en vano se opondrían los intereses y miras particulares a la voluntad de todos; en la "voluntad de todos" estaría encerrada la "verdadera opinión". Sin embargo, a nivel de la diacronía vertida por los sucesos ocurridos en la corta vida independiente, era claro que el concepto se confundía con una "falsa opinión", esgrimida por ambiciones particulares.

Ninguna medida que no sea de interés común, próxima y fácilmente perceptible, es objeto adecuado de la verdadera opinión pública [...] Esta

${ }^{34}$ El Sol, ediciones del 3 de agosto de 1825, núm. 781, pp. 199-200; 4 de agosto de 1825, núm. 782, pp. 202-204; 9 de agosto de 1825, núm. 788, pp. 223-224; 11 de agosto de 1825 , núm. 789, pp. 231-232; 12 de agosto de 1825, núm. 790, pp. 234-235.

${ }^{35}$ Decimos “curiosamente", porque el artículo es atribuido por Palti a José María Luis Mora. Aunque no es una imposibilidad la autoría de Mora, los editores de El Sol aclaran la fuente de los artículos publicados en su periódico: "Este excelente artículo, aunque tomado del Español Constitucional escrito para España, es tan adaptable a nuestras circunstancias que hemos creído deberlo insertar sin variación alguna. - Los E.E." El Sol 12 de agosto de 1825, núm. 790, pp. 234-235.

${ }^{36}$ El Sol, 3 de agosto de 1825, núm. 781, pp. 199-200.

${ }^{37}$ Loc. cit. 
regla segura nos debe servir para dar su justo valor a esas oleadas populares y tumultuarias, principios de las revoluciones y obra exclusiva de los ambiciosos demagogos: ellas nunca serán signo de la opinión pública y de la voluntad general, porque entre otras cualidades les faltará la estabilidad y firmeza; serán pensamientos y deseos momentáneos, casi siempre sugeridos por los perversos, pero no serán el deseo público. Una multitud excitada y fascinada aplaudirá en Roma la muerte de los Gracos; llevará en París a la guillotina a los hombres más ilustres y virtuosos; pedirá en México la elevación al trono de un caudillo pero ninguna de estas cosas serán efecto de la opinión pública, sino el 'eco de la seducción, el grito de pillos y rameras que subirá más alto, según se explica un periodista célebre, cuanto mejor lo hayan pagado los corifeos de los partidos' [...] Distinguimos, pues, cuidadosamente la voz popular de la opinión pública. La primera se forma con la misma facilidad que las nubes de primavera; pero con la misma se disipa. Es producida por el terror, por las facciones, por la ignorancia, por otras mil causas accidentales que pueden ser destruidas por sus opuestas. ${ }^{38}$ [Las cursivas son mías.]

Para evitar esta confusión en lo siguiente, los editores de El Sol partieron del mismo lugar que sostenía Zavala en El Hispano-Americano Constitucional, sobre el que hicimos referencia más arriba, y continúa El Sol diciendo que

no hay magistratura alguna que pueda obligarme a adoptar un principio de que no está convencida mi razón [...] No hay, pues, ni puede haber otro tribunal para decidir sobre materias de opinión pública, sino el tribunal de la razón y del sentido general de los hombres, cuando por la libre discusión y la ruina de los intereses de partidos se hallan en estado de juzgar sanamente. ${ }^{39}$

No obstante, la mayor parte de los ciudadanos, “ocupados en sus obligaciones domésticas, si bien son capaces de conocer la verdad cuando se les presenta con claridad y exactitud — no lo son de proponer

${ }^{38}$ Loc cit.; véase también El Observador de la República Mexicana, $1^{\circ}$ de agosto de 1827 , núm. 10, pp. 255-284.

${ }^{39}$ El Sol, 4 de agosto de 1825, núm. 782, pp. 202-204. 
ideas políticas, porque ni han hecho el estudio necesario para adquirirlas, ni tienen el hábito de ordenarlas".

Solamente los que se han entregado al estudio de las letras, tienen el caudal necesario de ideas y conocen el método de exponerlas [...] Los sabios, pues, deben ser el primer órgano de la opinión pública: esta es la primera y más sagrada de sus obligaciones: ellos ejercen la magistratura de la enseñanza [...] Todo gobierno debe animar a los sabios para que escriban e instruyan la nación: debe poner la más reflexiva atención a los trabajos que salen de sus manos, examinarlos, adoptar las verdades que demuestran y corregir los errores en que puedan caer. ${ }^{40}$

El punto de partida ayuda a reformular el concepto de opinión pública. Solo la discusión racional puede formar opinión pública; sin embargo, no todos los habitantes están instruidos para adentrarse en esa discusión. ¿Quiénes son estos virtuosos con el tiempo y capital necesario para la instrucción de ellos y su familia? Los propietarios, contesta sin dudar El Sol:

[A]prender, pues, naciones que queréis ser libres: formad un partido nacional, y haced que este partido se componga del todo de todos los ciudadanos útiles: de esta masa general de propietarios, de este pueblo instruido o que puede instruirse, en el cual es imposible suponer miras de ambición, miras funestas al bien público: porque su bienestar individual es el interés mismo de la patria. ${ }^{41}$

De esta forma, la pregunta sobre el cómo se transforma en la pregunta por los quiénes sustentan la opinión pública. El problema ya no radicaba en la manera de formarla, problema cabalmente resuelto, sino en cómo generar una operación de inclusión y al mismo tiempo expulsión del espacio público: inclusión en el sentido de unificar esa parte industriosa y propietaria del país, y expulsión en el sentido de sacar a esa "turba de escritores de mediana instrucción" que habían invadido una profesión solamente reservada a los "ciudadanos útiles". En esta

${ }^{40}$ Loc. cit.

${ }^{41}$ Ibid. 
operación — que radicalizó el enfrentamiento entre las facciones — se sustentaron los diferentes grupos para la formación de una opinión pública "verdadera". Circulantes dentro del espacio público, buscaron elevarlas como sustentadoras de la "verdad" y, lógicamente, los portadores de todas ellas se justificaron como portadores de la opinión pública.

Tras la polarización de la vida política mexicana entre 1826 y 1828 , la experiencia apuntaba, para algunos, a una pérdida de las expectativas centradas en la opinión pública; es decir, el optimismo puesto en la opinión pública como sustentadora de la "verdad" se fue perdiendo, al grado de que ciertos grupos plantearon la posibilidad de ceder la responsabilidad a un tercero que propiciara el espacio adecuado para la formación de la opinión pública. Sin embargo, no se perdió la finalidad ideal de la opinión pública, que había que aprovechar para la ilustración de la nación, aportar conocimientos útiles, llamar la atención a las autoridades que por ser hombres también podían equivocarse, pero sin caer en los excesos de los libelos infamatorios y atacar constantemente las bases constitucionales, la religión y la moral.

Más tarde, hacia mediados del siglo XIX, sostener la soberanía de la República en la opinión pública sería tomado como un imposible. Así lo manifestaba El Siglo XIX hacia 1848:

Al terminar la invasión norteamericana, cada clase y aun cada individuo ha formado una fracción; nunca las opciones habían sido tan numerosas, tan extremadas, se nos propone desde entregarnos a los extraños, hasta a la voluntad de un solo hombre; y cualquiera resolución de estas que se tomara, no solo sufriría grandes disputas de sus autores, sino que quedaría reducida a ser la voluntad de unos pocos. ${ }^{42}$

A mediados del siglo, para autores como Ignacio Ramírez el sustento de la legitimidad en una opinión pública era una ficción. No había para él una "opinión pública verdadera"; lo único que se observaba en la realidad — decía—, es que había opiniones diversas y contrarias. Siendo esto así: ¿se debería respetar la opinión pública? ¿Cuál de tantas debería respetarse? Por estas ideas, en 1849 El Universal consideraba

${ }^{42}$ Citado en Palti, op cit., p. 219. 
insostenible la idea del origen por medio de un acuerdo y contrato de la sociedad. Para 1851, esta pluralidad se expresó en una proliferación de candidatos a la presidencia. Cada periódico representante de alguna facción tenía el suyo, y ninguno obtendría por claras razones la mayoría. Los más importantes eran Nicolás Bravo, Juan Almonte, Manuel Gómez Pedraza, Luis de la Rosa y Mariano Arista, apoyados por El Universal, La Linterna de Diógenes, El Siglo XIX, El Demócrata y El Monitor Republicano, respectivamente. ${ }^{43}$

\section{Conclusiones}

La apertura del espacio público en los inicios de la vida independiente fue totalmente revolucionaria para la sociedad mexicana de la época, pues el establecimiento de la libertad de imprenta facilitó la circulación de periódicos en los que cualquier persona podía dar su opinión acerca de los asuntos de interés público. Sin embargo, muchos individuos mostraron su inconformidad por la amplia circulación de impresos que consideraban de "mal gusto", "groseros" y "vulgares". Muchos se dieron a la tarea de explicar qué era la opinión pública, qué se debía entender como opinión pública, cómo se formaba y quiénes se encargaban de formarla. El objetivo era generar un mecanismo de distinción que ayudara a discernir entre la "opinión pública verdadera" y la "opinión común y falsa".

Estas preocupaciones no eran banales, pues en el concepto opinión pública se trató de sustentar la legitimidad política y la soberanía de la nación mediante lo que concebían como espíritu público o voluntad general. De esta forma, la opinión pública era entendida como la reunión de las voluntades particulares que en pública discusión sobre los problemas que atañían al común diera las pautas para que la voluntad de la mayoría, la opinión general, la voluntad de todos, emergiera como la opinión pública. Sin embargo, después de las experiencias acumuladas y los caóticos acontecimientos que llevaron al trono a Agustín I,

${ }^{43}$ Palti, op. cit., especialmente el apartado "Los límites de la legalidad y el escape de lo trascendente", pp. 235-251. 
el problema de la opinión pública tendría que sufrir una restructuración. La pregunta sobre el cómo se transformó en la pregunta por quiénes sustentarían la opinión pública. El problema ya no radicaba en la manera de formarla, problema cabalmente resuelto, sino en cómo generar una operación de inclusión y al mismo tiempo expulsión del espacio público para la constitución de esa opinión.

Finalmente, la reflexión sobre el concepto de opinión pública nos llevó a un lugar que se encuentra más allá del significado del concepto. En su carácter semántico-sincrónico, es decir pragmático, generalmente va referido a una "verdad" surgida de una discusión pública; de esa forma, permitiría abrigar expectativas referidas a un posible estado de cosas futuras. Pero en su carácter existencial-diacrónico y polémico, el concepto conllevaba, en su sedimentación conceptual, preguntas y estados de cosas, además de ánimos generados por las experiencias recientes de la práctica política. ¿Cómo formar la opinión pública? ¿Cómo discernirla? ¿Quiénes están facultados para formar la opinión pública? Estas preguntas surgieron de tales experiencias. A mediados del siglo XIX, el concepto de opinión pública dejó de tener relevancia conceptual y política, y esto se evidencia en lo ilógico que resultaba para algunos tratar de sustentar la soberanía en una opinión pública "mítica". 